\title{
CONSIDERATION OF SEASONAL VARIATIONS OF WATER RADIOMETRIC INDICES FOR THE ESTIMATION OF SOIL MOISTURE CONTENT IN ARID ENVIRONMENT IN SAUDI ARABIA
}

\author{
BAHRAWI, J. A. - ElHAG, M.* \\ Department of Hydrology and Water Resources Management, Faculty of Meteorology, \\ Environment \& Arid Land Agriculture, King Abdulaziz University \\ 21589 Jeddah, Kingdom of Saudi Arabia \\ *Corresponding author \\ e-mail: melhag@kau.edu.sa
}

(Received $11^{\text {th }}$ Aug 2018; accepted $31^{\text {st }}$ Oct 2018)

\begin{abstract}
Remote Sensing applications in agricultural practices are comprehensively reliable and cover a multidisciplinary fundamental interest on a local as well as on a regional level. Significantly, vegetation indices are foremost essential remote sensing applications in agricultural activities related to vegetation and/or water, particularly in an arid environment. Adequate water resources management plans are based on better fulfilment of water demand and supply equation. In arid environments, this equation is barely achieved due to water resources limitations. Remote sensing techniques improve the water resources management schemes using five different water radiometric indices of Sentinel-2. Each of them plays a specific role in the quantification of soil/plant water content based on the interpretation of map surface water features and monitors the dynamic of surface water. The study area is located within the main agricultural region of Wadi As-Sirhan, Saudi Arabia. The area is characterized by flourishing agricultural activities. Remote Sensing data acquired by Sentinel-2 proved to be statistically sufficient to estimate soil water content in two different climatic conditions. Statistically, winter estimated indices are a better fit than summer indices. MNDWI and NDWI-2 were best to fit winter soil water content estimations. Meanwhile, RMSE shows no differences between NDWI and NDTI in both climatic conditions.
\end{abstract}

Keywords: integrated water resources management, Sentinel-2, soil water content, remote sensing, water radiometric indices

\section{Introduction}

The Kingdom of Saudi Arabia (KSA) has a very low annual precipitation, high temperature, no lakes or flowing rivers and classified as an arid region. Water, therefore, is infrequent and enormously valuable, especially in a country with rapid growth in which the water demands are cumulative. The scarcity of fresh water resources presents the primary difficulty to the existence of biotic life in Saudi Arabia (Elhag, 2016). Generally, the average annual rainfall is closely less than $80 \mathrm{~mm}$, with a sporadic maximum annual rainfall that exceeds $500 \mathrm{~mm}$, particularly in the southwestern region (Bahrawi et al., 2016).

Saudi Arabia has experienced an elevated development in all divisions over the last four decades. As a result, a swift intensification in agricultural, industrial and domestic water demands have been perceived. Agriculture is the major water consumption sector as it consumes about $85 \%$ of the total national water use (Elhag and Bahrawi, 2014a, 2017a). The government of Saudi Arabia subsidized the agricultural sector during the period 1974-2006 to improve the standard of living in rural areas and to attain selfsufficiency. 
Soil water content depends on many parameters that are spatially and temporally variable such as soil type, vegetation cover, crop type, topography, and precipitation. Considering all these variable factors and collecting sufficient measurement data for the account of the spatial variations of the vadose zone soil water content is neither financially nor technically practical (Şen et al., 2017).

Soil water content is the amount of water available for plants uptake at the root zone; coarsely this zone is less than $50 \mathrm{~cm}$ of depth (Zhu et al., 2008). Within this thin layer, several important biological and hydrological essential processes take place (Crippen, 1990; Walker, 1999). It is very crucial to monitor this layer to ensure plants survival (Su et al., 1995). Traditional methods of soil water content estimation are usually valid for a small local level like a farm, but it always costs time and effort and is not a sufficient method to estimate spatial and temporal variations of soil water content on a regional scale (Engman, 1991; Wood et al., 1992; Watson et al., 2017).

Remote sensing techniques are now widely used to forecast, monitor and estimate soil water content (Ochsner et al., 2013; Psilovikos and Elhag, 2013). Estimation of soil water content using remote sensing practices is different and generally falls into two groups of methods: 1- passive remote sensing method of estimation and 2- active remote sensing method of estimation (Palecki and Bell, 2013). Both techniques depend on the capability of a certain wavelength to penetrate the root zone and register its reflection (Myneni et al., 1995; Dasgupta, 2007). Short Wave InfraRed (SWIR) wavelength can shallowly penetrate the root zone and SWIR is either registered passively from the sun or actively using Ground Penetration Radar (GPR) systems (Gao, 1996; Moghadas et al., 2013).

Low crop productivity is highly related to the availability of water resources. To optimize the use of limited water resources in arid environments unconventional methods of planning are required (Elhag and Bahrawi, 2017b). Soil water monitoring is a crucial feature of managing water requirements of agricultural fields founded on advanced irrigation techniques (Muñoz-Carpena et al., 2002). The main goal of farmers and decision makers is to keep soil water content within optimized range for better crop production, unsaturated soil, and efficient crop production are challenging (MuñozCarpena et al., 2005; Elhag and Bahrawi, 2014b).

Relevant research studies were conducted in similar arid environments. Modified Normalized Difference Water Index was investigated by Zhang and Huai-Liang (2016) to monitor drought condition. Mathieu et al. (1998) were pioneers to study the relationship between laboratory reflectance data and remote sensing data. Other significant scholarly work was conducted by Elhag and Bahrawi (2017b) to assess the hydrological drought indices in other parts of Saudi Arabia.

Several radiometric water indices have been developed within the past few decades. Principally, McFeeters (1996) projected the Normalized Difference Water Index (NDWI). The index utilizes the Green and the Near Infrared bands of remote sensing data. The index was projected to improve the extracted information from the remote sensing data regarding the soil moisture content. Lately, Modified Normalized Difference Water Index (MNDWI) was developed by Xu (2006) to improve the limitations of NDWI, where the Shortwave Infrared was used instead of NIR band. Several academic researches conducted by Xu (2006), Li et al. (2013), Du et al. (2014) and Singh et al. (2015) MNDWI is considered to be a better radiometric water index over NDWI. 
Remote sensing techniques provide the tool to estimate soil water content on a large scale in time and in a cost-effective manner (Chauhan, 2003). Irrigation network in the designated area relays on advanced sprinkling irrigation systems. The huge plant water requirement in the study region is supplied from the underlying groundwater aquifer. Spatial correlation between soil water content and vegetation stress may alter the strategy of water management in the study area (Mustafa and Rahman, 2018). Image correction is a preliminary procedure in digital image analysis. Atmospheric and radiometric correction techniques are essential steps. According to Chavez (1996) and Thompson et al. (2018), Atmospheric correction depends on the calibrated radiance value of these offset consents to decide the $\kappa$ value. The $\kappa$ decision rule is based specifically on the flying height. The $\lambda^{-\mathrm{K}}$ determines the offset values for the Green, Red and Near Infra-Red band calibration (Beisl et al., 2008). Moreover, radiometric correction is required to harmonize the conducted measurements made with a variety of different satellite sensors under different environmental conditions (Zhu et al., 2015).

The main objective of the current research work is to contemplate the regression correlation between the values of Remotely Sensed water radiometric indices conducted from satellite images and ground truth data. Regression analysis will be considered under seasonal variation from winter to summer to understand the effect of seasonality on the estimation of the water radiometric indices. Therefore, accurate synchronization of ground truth data collection and satellite bypassing were exercised to maximize the use of the irrigational water in the study area.

\section{Materials and methods}

\section{Study area}

The Wadi As-Sirhan or Sirhan is a valley located in the northwestern part of Saudi Arabia and extends from north-west Saudi Arabia to eastern Jordan (from Lat $30^{\circ} 45^{\prime}$ to $29^{\circ} 30^{\prime} \mathrm{N}$ and from Long $37^{\circ} 50^{\prime}$ to $39^{\circ} 30^{\prime} \mathrm{E}$ ). The Wadi is a high-altitude area with a height of about 500 to 700 meters above sea level, and with a total area of about 9000 $\mathrm{km}^{2}$ and a length of more than $300 \mathrm{~km}$, while the width of the valley is between 15 to 50 kilometers (Fig. 1). It is in the west-central part of the Sirhan turayf basin and is underlain by Silurian to Miocene-Pliocene sedimentary rocks that are partly covered by volcanic flows. The map area also contains large areas of surficial sand and gravel. Wadi As-Sirhan is characterized by 5 Million Cubic Meter (MCM) annual flow and 18 MCM annual discharge and safe yield of 7-10 MCM/yr (Bahrawi and Elhag, 2016). Hydrogeological investigations in Saudi Arabia demonstrate that groundwater is stored in more than 20 primary and secondary aquifers (Hoetzl, 1995). It has been estimated that the groundwater reserves are about $210,000 \mathrm{~m}^{3}$ of which $17500 \mathrm{~m}^{3}$ is stored in deeper secondary reserves (Al-Rashed and Sherif, 2000). The total volume of groundwater abstracted for irrigation in the designated study area has increased from 23 MCM in 1973 to 2,051 MCM in 2006, while the annual recharge does not exceed $10 \%$ (Elhag and Bahrawi, 2014a). The climate in the study area is confined to the semi-arid climate. About $80 \%$ of the study area receives less than $100 \mathrm{~mm} / \mathrm{yr}$, mostly during the spring months (Şen et al., 2017). The area of Wadi As-Sirhan is characterized by very hot summers, average monthly maximum/minimum in July: $33.9{ }^{\circ} \mathrm{C} / 17.7{ }^{\circ} \mathrm{C}$, and mild winters, average monthly maximum/minimum in January: $14.7{ }^{\circ} \mathrm{C} / 3.8{ }^{\circ} \mathrm{C}$. The calculated annual potential evapotranspiration (ETo), Penman-Monteith approach (FAO, 1998) for Wadi As-Sirhan is $2,643 \mathrm{~mm} / \mathrm{yr}$. The soil of the study area is generally 
sandy soil with pH of 6.65 up to 7.4 and with Electric Conductivity EC of 0.031 up to $1.634 \mathrm{~ms} / \mathrm{cm}$. There were no significant differences in soil colors either in dry summer soils or wet winter soils. Organic matter content is identified to be low $(2.11 \%)$. The study area is not covered by natural vegetation. Mainly it is a reclaimed land for crop production. Water radiometric indices interpretation are exercised based on the ratios among the Red, Near Infra-Red and Infra-Red bands of Sentinel-2 over the study acquired in 2016.

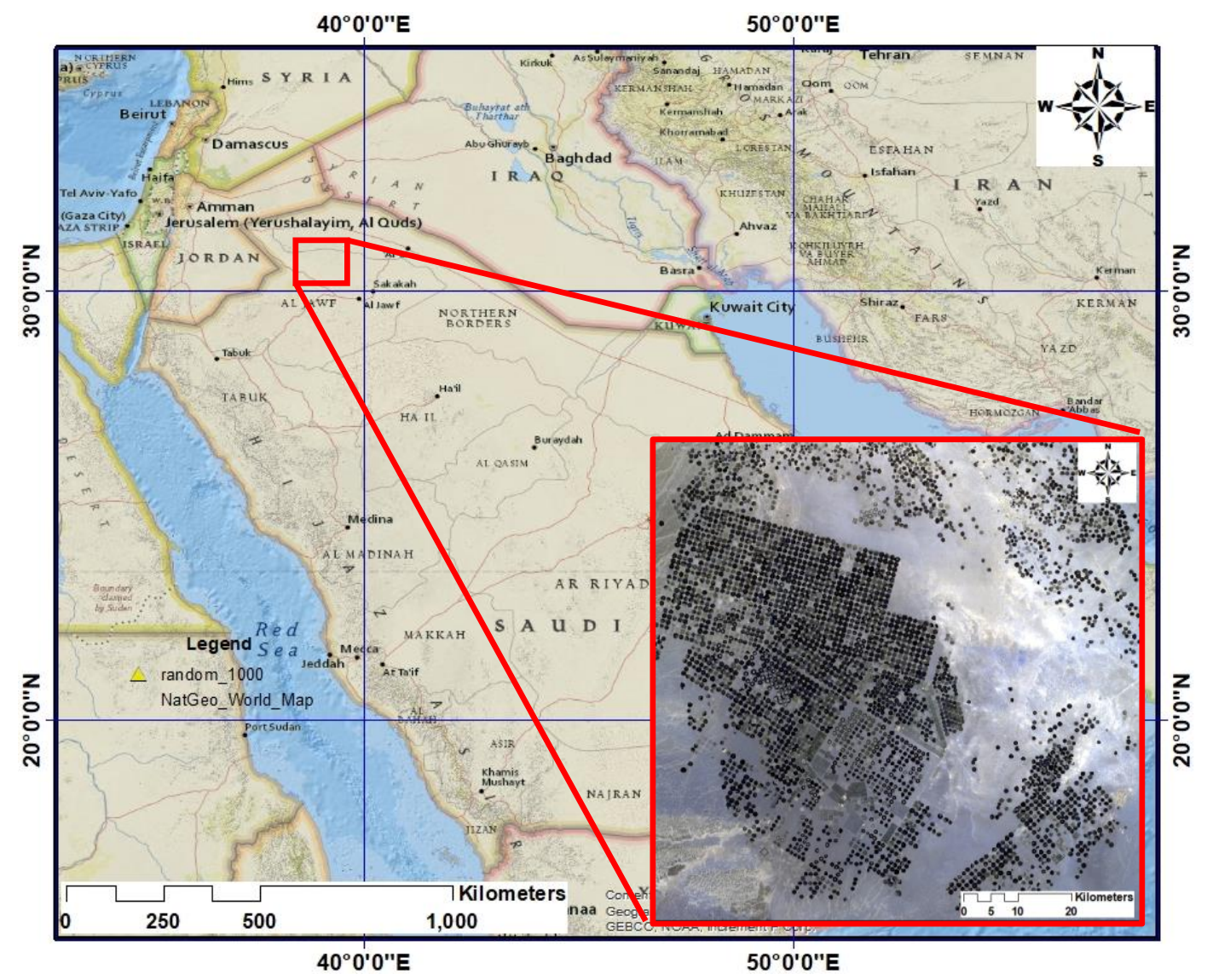

Figure 1. Study area location in false-color composite over a natural color base map

\section{Methodological framework}

Dataset and soil sampling

A total number of 150 random soil samples were collected from the cultivated land in Wadi As-Sirhan area with a minimum distance of $1000 \mathrm{~m}$ between the location of the samples to avoid data clumping and only bare soil locations were considered, not with crop cover. Soil samples were taken from soil surface level to $10 \mathrm{~cm}$ depth then mixed well for soil moisture estimation in triads to obtain the average. Samples were kept in sealed plastic packs and weighed in-situ for accurate estimation of soil moisture content (Elhag and Bahrawi, 2017b). Winter samples were collected in accordance with the bypass of the Sentinel-2 sensor (January 2016), and their locations were marked with wooden sticks for summer data collection (July 2016) as demonstrated in Figure 2. Sentinel-2 images were synchronized to soil samples collection and were downloaded 
and processed to represent the winter and the summer seasons correspondingly. Sentinel-2 is made of 12 spectral bands with a $10 \mathrm{~m}$ resolution of Visible bands (VI), $20 \mathrm{~m}$ resolution of Vegetation Red Edge (VRE) bands and Short-Wave InfraRed (SWIR) bands in addition to 3 bands related to coastal aerosols and water vapor of $60 \mathrm{~m}$ resolution. The Remotely Sensed water radiometric indices are conducted from several algorithms that examines basically the VI, VRE, and SWIR bands.

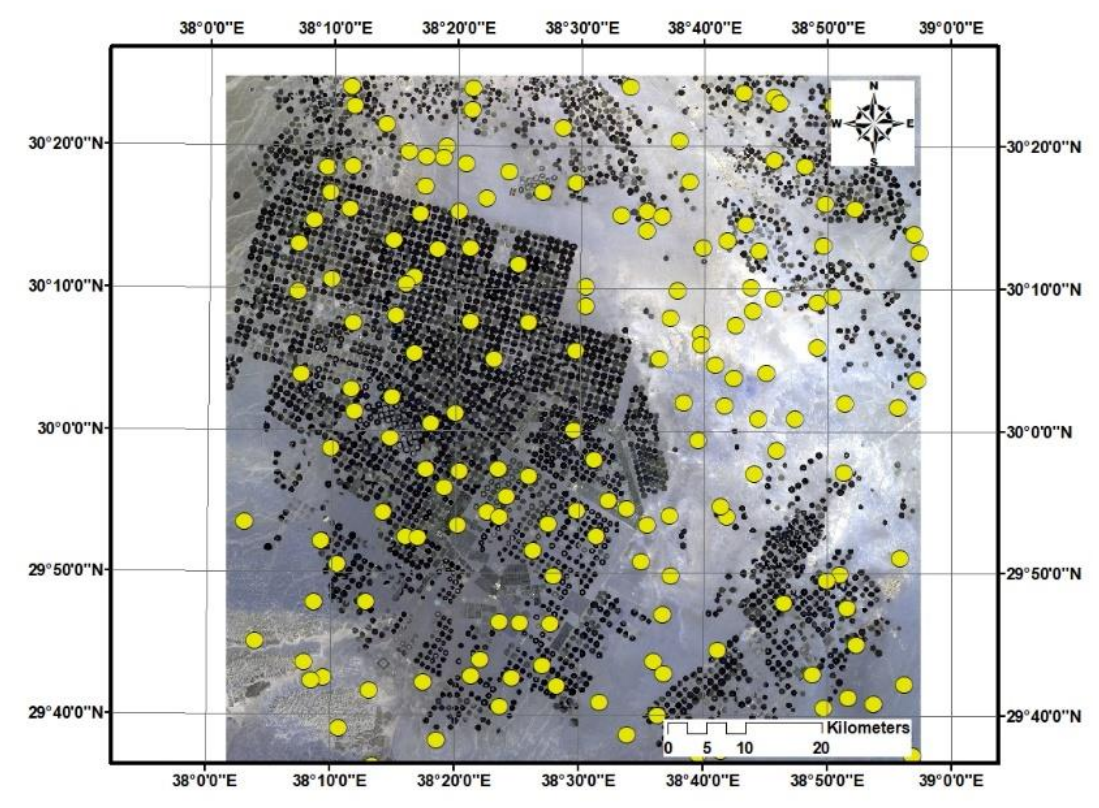

Figure 2. Soil sample location in a false color composition of Sentinel-2

\section{Estimation of soil water content}

This study adopted the common gravimetric method of soil water content estimation. The soil water content is expressed either in term of weight or volume. In the current research study, the soil water content is expressed in term of weight as the ratio of the mass between dry soil weight and wet soil weight. Determination of the soil water weight ratio is carried out by drying the soil to a constant weight and calculating the soil sample mass after and before drying. The criterion for drying the soil samples to a constant weight is considered after heat treatment in an oven at temperature between $100-110^{\circ} \mathrm{C}$. Within this range of temperature, it is assured that the water content in the examined samples will be evaporated without any alteration that may occur in the physical or the chemical characteristics of the soil samples. The soil water content in the dry weight approach is calculated following the formula (Eq. 1; Klute, 1986):

$$
\theta_{d}=\frac{\text { wt of wet soil-wt of dry soil }}{\text { wt of dry soil }}
$$

Soil water content is calculated as the ratio of water mass and the mass of wet soil $\left(\theta_{\mathrm{w}}\right)$. The alteration from $\theta_{\mathrm{d}}$ to $\theta_{\mathrm{w}}$ can be calculated as follows $(E q .2)$ :

$$
\theta_{d}=\frac{\text { wt of water }}{\text { wt of dry soil }}
$$




$$
-290-
$$

After manipulation, the water content in wet and dry basis can be expressed as (Eq. 3):

and $(E q .4)$

$$
\theta_{d}=\frac{\theta_{w}}{1-\theta_{w}}
$$

$$
\theta_{w}=\frac{\theta_{d}}{\theta_{d}+1}
$$

Remote sensing analysis

The amount of water present in leaf internal structure mainly affects the spectral reflectance in the Short-Wave InfraRed (SWIR) interval (ca. 1.2-1.7 $\mu \mathrm{m}$ ). The SWIR reflectance is also sensitive to the canopy internal structure. Because the NIR is exaggerated by leaf internal structure and leaf dry matter, but not by the water content, the combination of SWIR and NIR into NDWI calculation removes the leaf dry matter and internal structure and retains the water content. NDWI is less susceptible to atmospheric scattering than NDVI, but it cannot eliminate totally the effects of the background soil reflectance's comparable to NDVI.

The Modified Normalized Difference Water Index (MNDWI) algorithm was developed by $(\mathrm{Xu}, 2006)$ to improve the open water features through an efficient elimination of land noise as well as vegetation and soil noise. MNDWI is calculated by Equation 5:

$$
M N D W I=\frac{\text { Green }- \text { SWIR }}{\text { Green }+ \text { SWIR }}
$$

where:

Green is Sentinel-2 Green Band SWIS is Sentinel-2 Short-Wave InfraRed Band

The Normalized Difference Pond Index (NDPI) was developed by (Lacaux et al., 2007) to distinguish the vegetation cover from its aquatic surroundings. NDPI is calculated by Equation 6:

$$
N D P I=\frac{\text { SWIR }- \text { Green }}{\text { SWIR }+ \text { Green }}
$$

where:

SWIS is Sentinel-2 Short-Wave InfraRed Band

Green is Sentinel-2 Green Band

The Normalized Difference Turbidity Index (NDTI) was developed by (Lacaux et al., 2007) to estimate water turbidity. NDTI is calculated by Equation 7:

$$
N D T I=\frac{\text { Red }- \text { Green }}{\text { Red }+ \text { Green }}
$$

where

Red is Sentinel-2 Red Band

Green is Sentinel-2 Green Band 
The Normalized Difference Water Index (NDWI) was found by Gao (1996) Then improved by Ganaie et al. (2013) to measure the liquid water molecules at the Top Of Canopy (TOC) level. NDWI is calculated by Equation 8:

$$
N D W I=\frac{N I R-S W I R}{N I R+S W I R}
$$

where

NIR is Sentinel-2 Near InfraRed Band

SWIS is Sentinel-2 Short-Wave InfraRed Band

The second Normalized Difference Water Index (NDWI-2) was developed by McFeeters (1996) to detect and measure the surface water extent in addition to the surface water of wetland environments. NDWI-2 is calculated by Equation 9:

$$
\text { NDWI }-2=\frac{\text { Green }- \text { NIR }}{\text { Green }+ \text { NIR }}
$$

where

Green is Sentinel-2 Green Band

NIR is Sentinel-2 Near InfraRed Band

The final step in image data analysis in the current study is data normalization. The above-mentioned Water Radiometric Indices are calculated within a range of -1 to +1 . Therefore, Water Radiometric Indices were transformed into the same range of soil water content weights for comparability reasons using Hawkins and Pole (1989) transformation (Eq. 10):

$$
z=\frac{1}{2} \ln \left(\frac{1+r}{1-r}\right)=\operatorname{arctanh}(r)
$$

where

ln is the natural logarithm function

arctanh is the inverse hyperbolic tangent function

$r$ is the Fisher's z-transformation

\section{Regression analyses}

The purpose of the regression analysis is to envisage the regression potentials between soil salinity index from one side and the rest of the hydrological drought indices from the other side. Principle Component Analysis (PCA) is performed to transform a set of likely correlated variables with unlikely correlated variables. Principal components number is less/equal to the variables original number. Following Monahan (2000), PCA fundamental equations are (Eqs. 11-13):

First vector $w_{(1)}$ should be answered as follows:

$$
w_{(1)}=\arg \max x_{\|w\|=1}\left\{\sum_{i}\left(t_{1}\right)_{(i)}^{2}\right\}=\arg \max _{\|w\|=1}\left\{\sum_{i}\left(x_{i} \cdot w\right)^{2}\right\}
$$

The matrix form of the above equation gives the following:

$$
w_{(1)}=\arg \max _{\|w\|=1}\left\{\|X w\|^{2}\right\}=\arg \max _{\|w\|=1}\left\{w^{T} X^{T} X w\right\}
$$


$w_{(1)}$ should be answered as follows:

$$
w_{(1)}=\operatorname{argmax}\left\{\frac{w^{T} x^{T} w_{w}}{w^{T} w}\right\}
$$

Originated $w_{(1)}$ suggests that first component of a data vector $x_{(\mathrm{i})}$ can then be expressed as a score of $t l_{(\mathrm{i})}=x_{(\mathrm{i})} \cdot w_{(1)}$ in the transformed coordinates, or as the corresponding vector in the original variables, $\left(x_{(\mathrm{i})} \cdot w_{(1)}\right) w_{(1)}$.

\section{Validation}

Validation of Water Radiometric Indices values was carried out using the ground truth data collection. 150 soil samples were analyzed for gravimetric soil water content and plotted against the remotely sensed values. The average accuracy is estimated by a horizontal function of the tested dataset. The average reliability is estimated by a vertical function of the tested dataset. The overall efficiency is estimated the diagonal function of the tested dataset. Following Congalton et al. (1983), a correspondence analysis $(C A)$ was constructed as follows $(E q .14)$ :

$$
C A=\frac{N \sum_{i=1}^{r} x i i-\sum_{i=1}^{r}(x i j k x j i)}{N^{2}-\sum_{i=1}^{r}(x i j k x i)}
$$

where

$r$, the number of rows in the error matrix

$x_{i i}$, the number of observations in row $\mathrm{i}$ and column i (the diagonal cells)

$x_{i+}$, total observations of row $\mathrm{i}$

$x_{+I}$, total observations of column $\mathrm{i}$

$N$, a total of observations in the matrix

\section{Results and discussion}

Realization of different water radiometric indices was computed succeeding to adequate atmospheric and radiometric corrections. Spatial distribution of the implemented water radiometric indices and their corresponding temporal acquisitions are illustrated in Figure 3a-e. The first dataset was comprehended for winter water radiometric indices (January 2016) then six months later (July 2016) the analysis procedures were repeated for the summer dataset (Fig. $3 f-j$ ).

Field data collection and remote sensing techniques were practiced with precise synchronization to optimize the results. Soil water content collected from summer then later winter seasons shows a significant correlation RMSE 0.01. Therefore, the agricultural practice in the designated study area suggests an equivalent amount of the irrigational water utilized in both seasons (Elhag, 2016; Elhag and Bahrawi, 2017b).

Water radiometric indices conducted from remote sensing data showed inconsistency responses between winter and summer seasons (Table 1 and Fig. 4a,b).

The estimated radiometric indices tend to respond preferably in winter rather than summer climatic condition (Fig. 5a). MNDWI shows a coherent pattern of estimation in different seasons. Such behavior could be considered as a lack of index sensitivity in the 
summer season rather than in the winter season as it agreed with Wang et al. (2013) and Gautam et al. (2015).

NDPI shows an idealistic correlation between the two seasons (Fig. 5b). Henceforward, the only foreseen explanation is that there is no ponds formation in the study area and that is why the index cannot differentiate the seasonality dissimilarities. Consequently, NDPI can be exercised all year long with no season preferences ( $\mathrm{Ji}$ et al., 2009; Dambach et al., 2012).
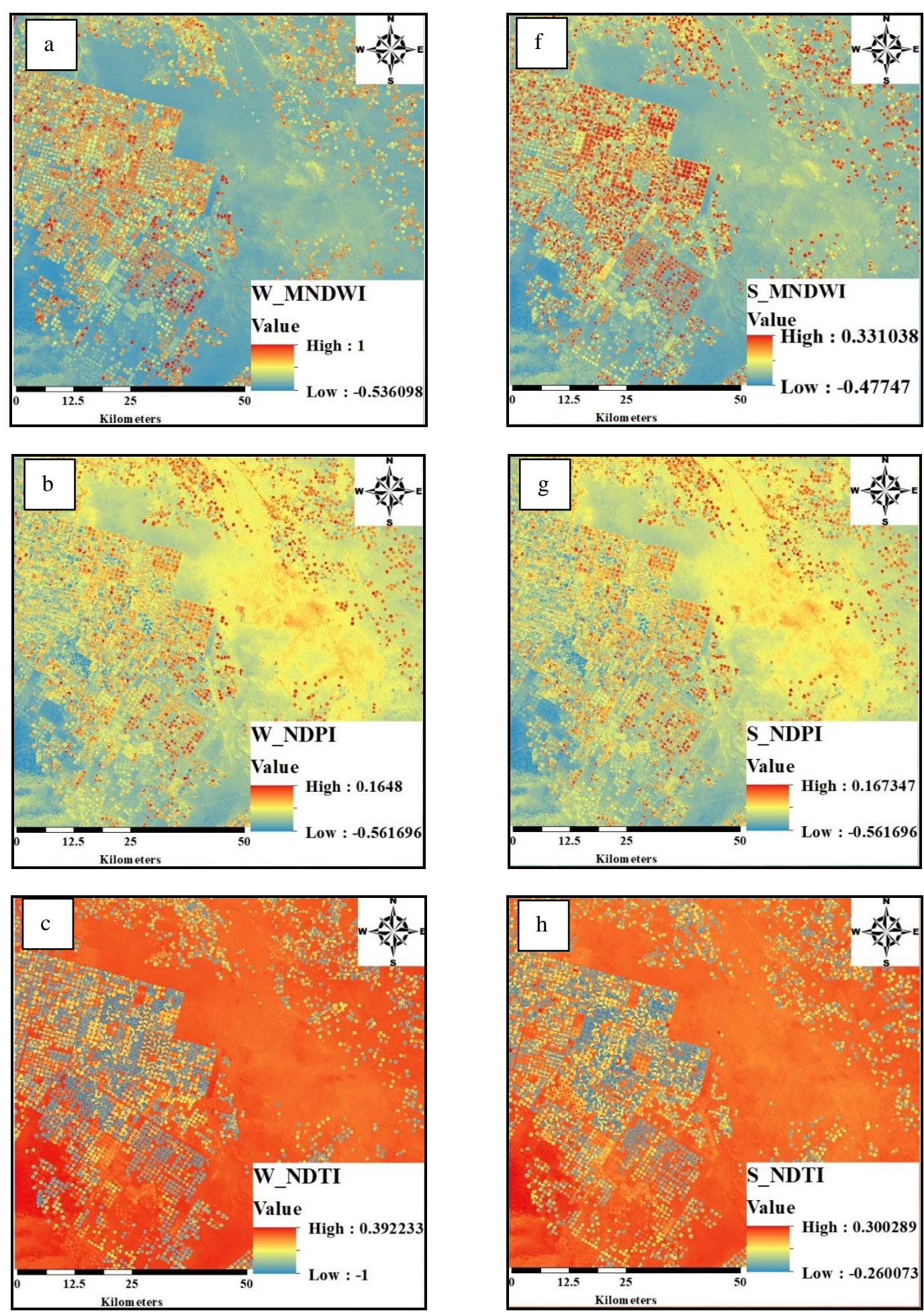

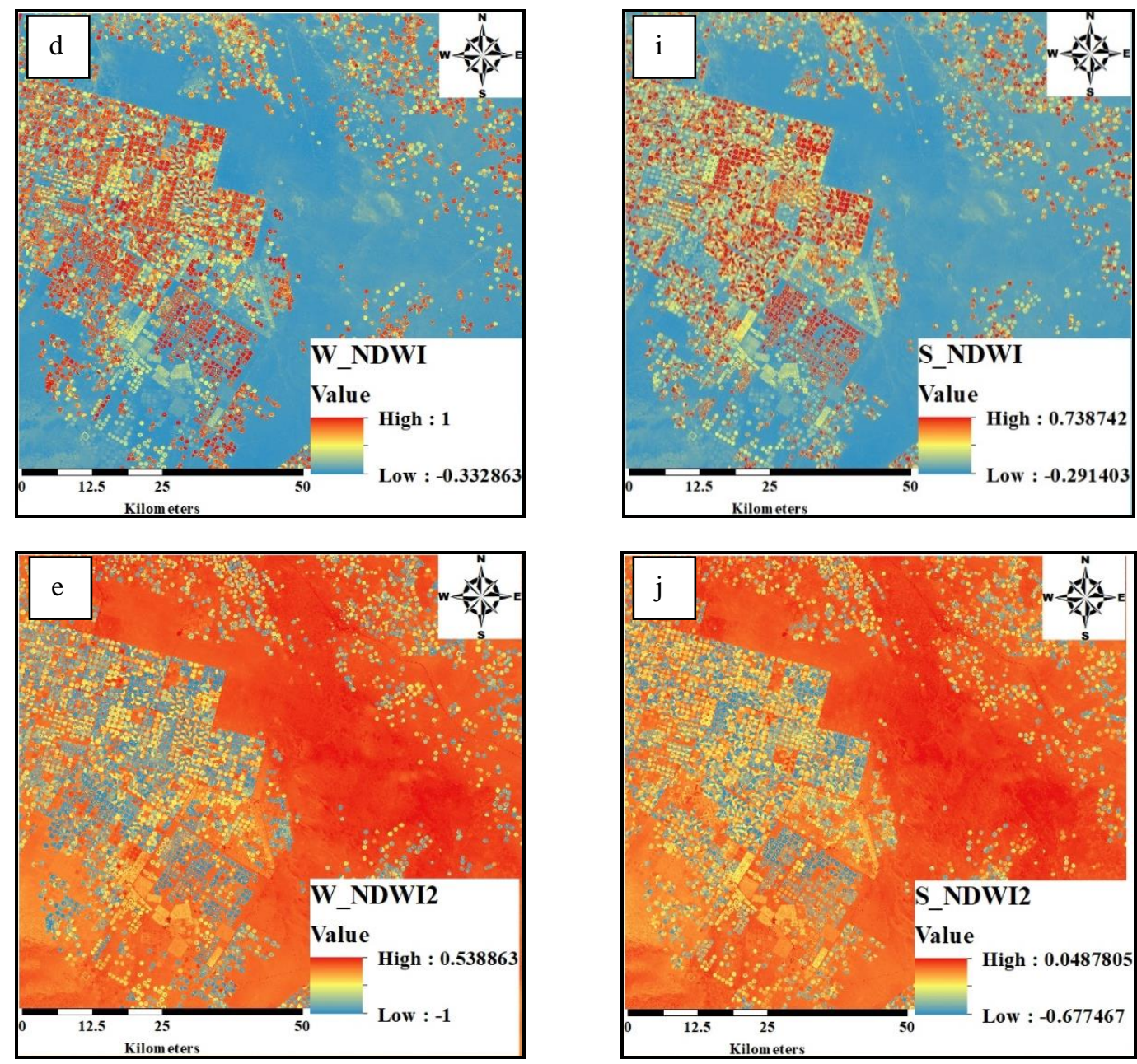

Figure 3. Spatial distribution of five different water radiometric indices in two different seasons (January as a winter season and July as a summer season-2016). a-e winter samples (W) and $\boldsymbol{f}$-j summer samples $(S)$

Table 1. Statistical analysis of the estimated radiometric water indices

\begin{tabular}{c|c|c|c|c|c|c}
\hline & \multicolumn{3}{|c|}{ Summer indices } & \multicolumn{3}{c}{ Winter indices } \\
\cline { 2 - 7 } & $\mathbf{R}^{\mathbf{2}}$ & $\mathbf{R M S E}$ & Equation & $\mathbf{R}^{\mathbf{2}}$ & $\mathbf{R M S E}$ & Equation \\
\hline MNDWI & 0.6117 & 0.08 & $0.3232 \mathrm{x}-0.4061$ & 0.7146 & 0.06 & $0.3813 \mathrm{x}-0.4643$ \\
NDPI & 0.9046 & 0.01 & $0.1432 \mathrm{x}-0.4365$ & 0.9476 & 0.01 & $0.1642 \mathrm{x}-0.4439$ \\
NDTI & 0.5397 & 0.07 & $0.258 \mathrm{x}+0.0287$ & 0.5859 & 0.08 & $0.3574 \mathrm{x}-0.0029$ \\
NDWI & 0.4916 & 0.15 & $0.5033 \mathrm{x}-0.1983$ & 0.5501 & 0.15 & $0.6539 \mathrm{x}-0.2522$ \\
NDWI-2 & 0.5718 & 0.07 & $0.2702 \mathrm{x}-0.4212$ & 0.6455 & 0.07 & $0.3747 \mathrm{x}-0.5051$ \\
\hline
\end{tabular}

On the other side, NDTI shows steady correlation along with the seasonal variations (Fig. 5c). NDTI is the only index that showed optimum correlation stability among other radiometric water indices. Accordingly, NDTI behavior is explained by the lack of pure water surfaces and irrigational water is considered as turbid water as it is mixed with soil particles at the surface level as it is confirmed by other scholarly works (Daughtry et al., 2005; Serbin et al., 2009). 


$$
-295 \text { - }
$$
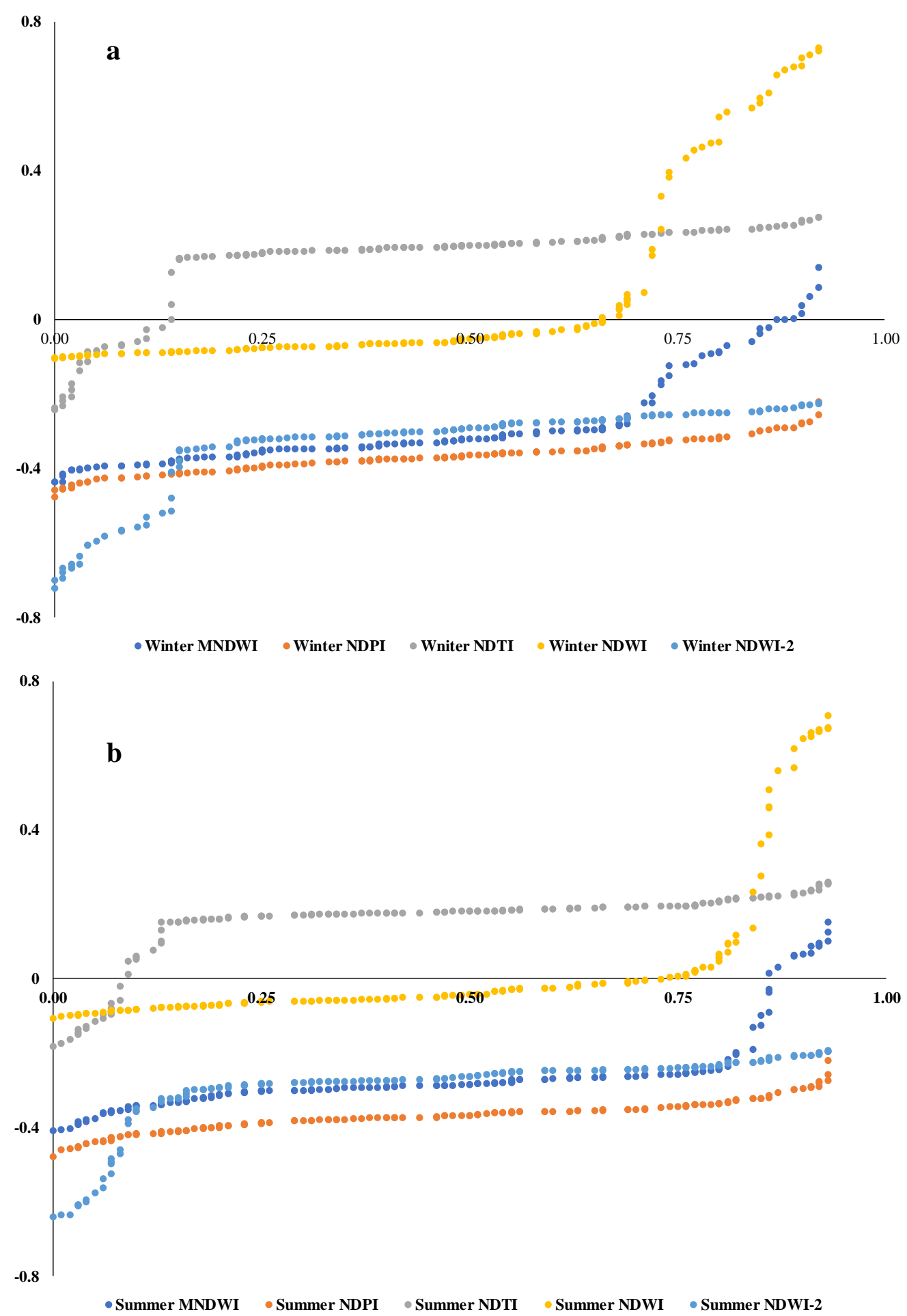

Figure 4. Seasonal variation of the estimated radiometric water indices (a for winter and $\boldsymbol{b}$ for summer)

Similar behavior to NDTI but with less accuracy is expressed by NDWI. NDWI shows a robust correlation with lower NDWI values rather than with higher values (Fig. 5d). Such results may promote NDWI to be used in winter rather than in summer conditions (Chen, 2006; Gu et al., 2007). 


$$
-296 \text { - }
$$

In contrary, the improved index of NDWI was exercised to contradict the sensitivity of the index to the seasonal conditions. NDWI-2 shows significant correlations in summer conditions with no winter condition preferences (Fig. 5e). Therefore, NDWI-2 could be considered as a summer index according to Soti et al. (2009) and Sánchez-Ruiz et al. (2014).

(a) MNDWI
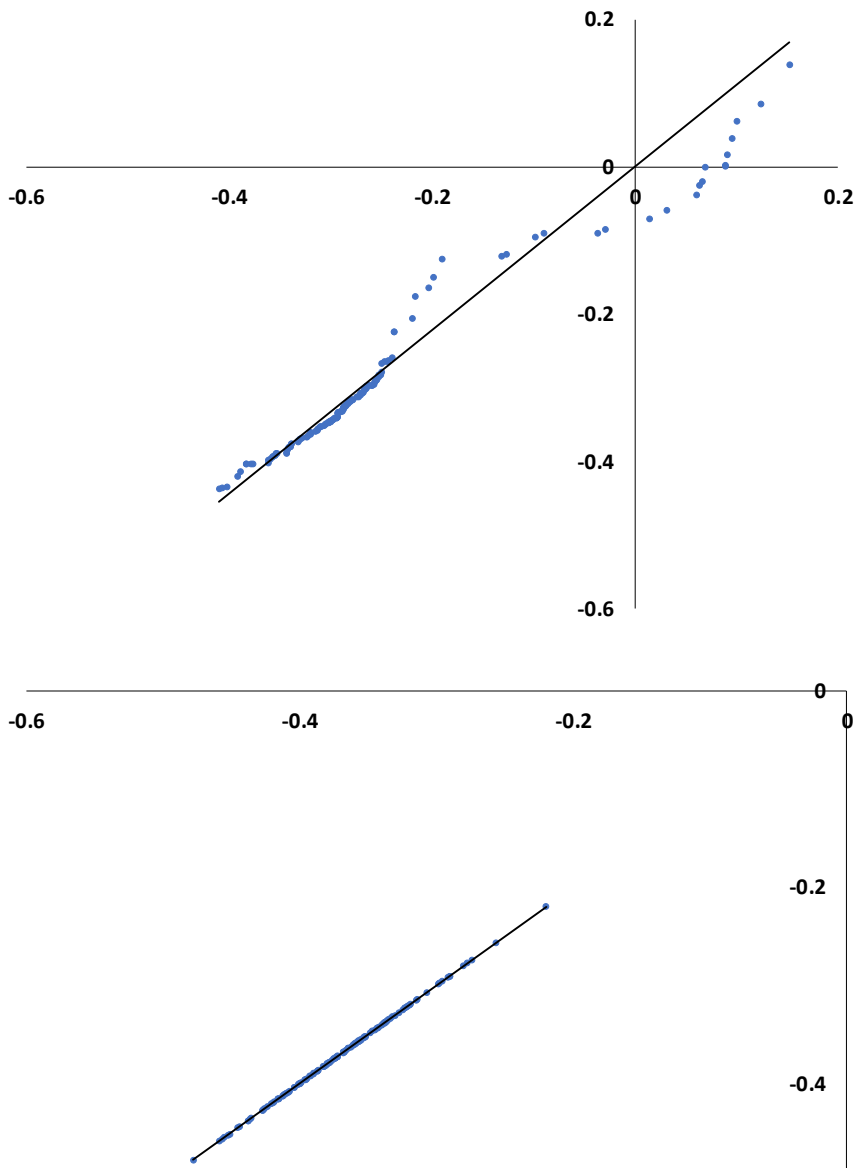

(b) NDPI $-0.6$

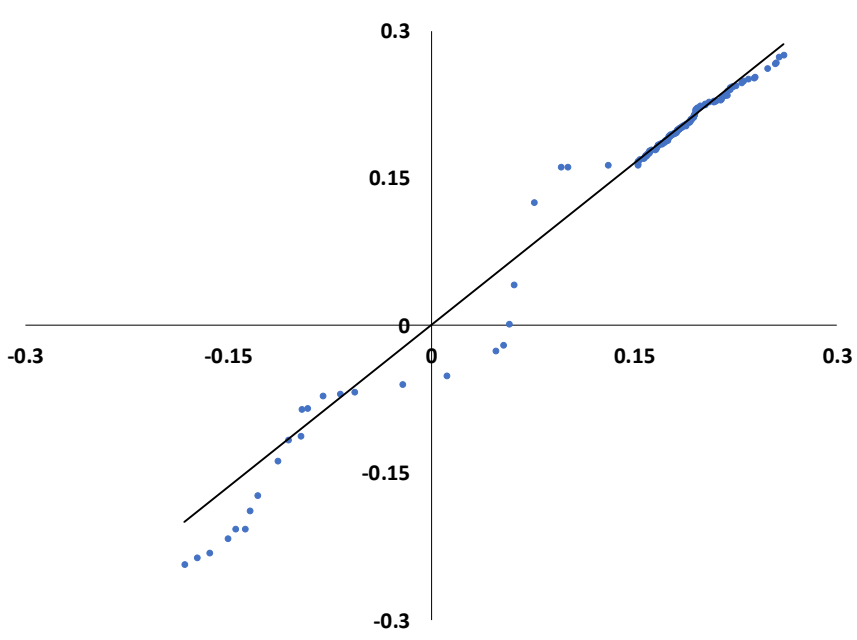




\section{(d) NDWI}
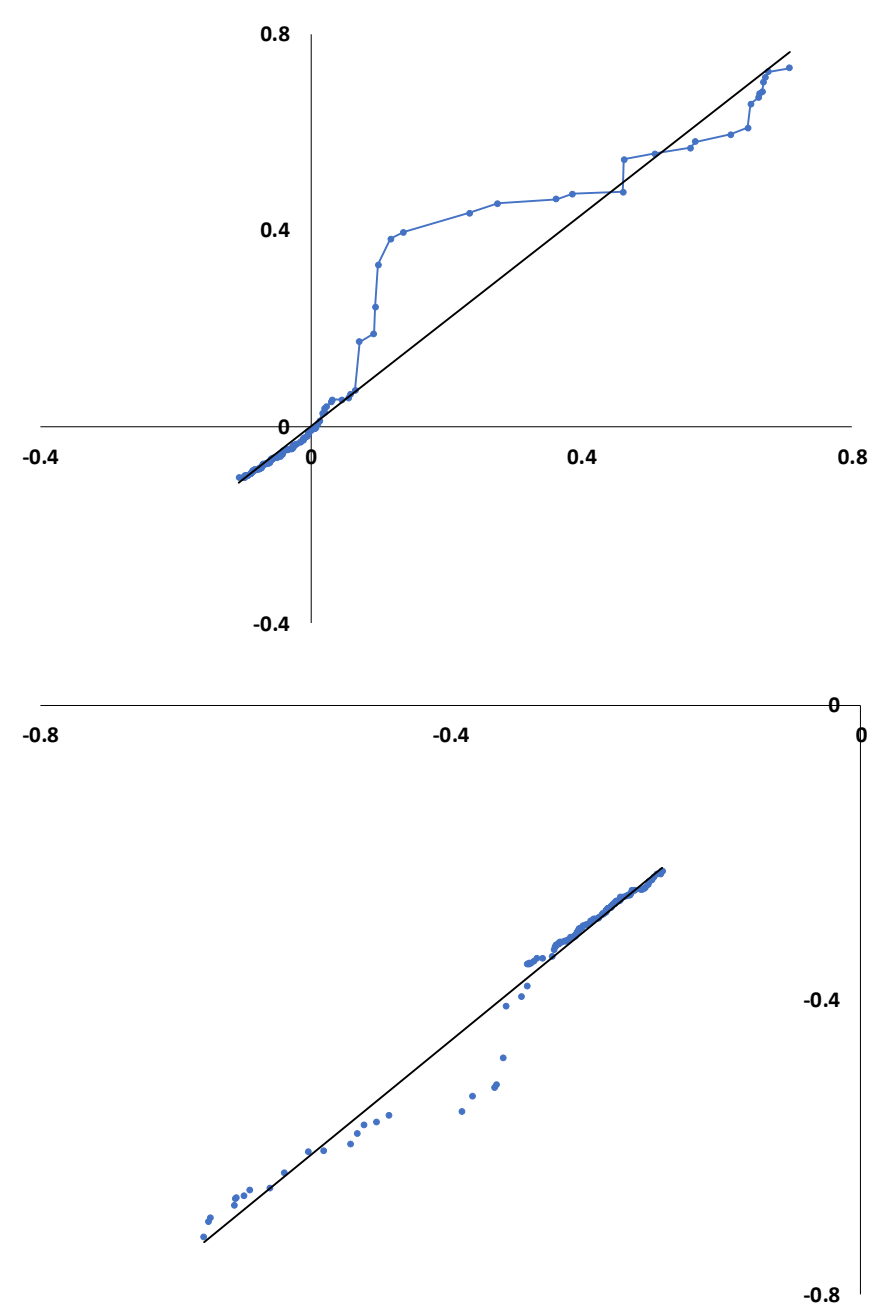

(e) NDWI-2

Figure 5. Seasonal radiometric water indices intercorrelation ( $x$-axis is the winter measurements; $y$-axis is the summer measurements)

Principally, the water radiometric indices used in the current research are varied based on the utilized bands in each rationing. Therefore, categorization of different indices using principal component analysis will help to examine the indices discrepancies (Gidey et al., 2018). Figure 5 represents the grouping of different indices according to principal component analysis on covariances in both seasons.

Generally, different water radiometric indices fell into two groups in both seasons. The first group contained NDPI and it showed no seasonal variation and kept a neutral behavior. Meanwhile, NDTI from one side and NDWI and MNDWI from the other side showed an alternative behavior across the two seasons (Fig. 6). Additionally, NDWI-2 is significantly correlated and grouped together (Table 2). Consequently, NDWI-2 is a superposed group (Dehni and Lounis, 2012). Lack of correlation is the main reason of NDTI and NDWI insignificance (Table 2). The implemented band length is the driving force of the correlation inconsequentiality between the previously mentioned indices (Lillesand et al., 2014).

The dynamicity of the soil water content dissimilarities proved by the seasonal variations added further complications to designate soil water content in a systematic 
uniform perspective. The use of different algorithms based on implementing different combinations and/or ratios of Sentinel-2 bands in the form of water radiometric indices evidenced to be more efficient to overcome water dynamicity problems (Lei et al., 2014; Zhang et al., 2015).

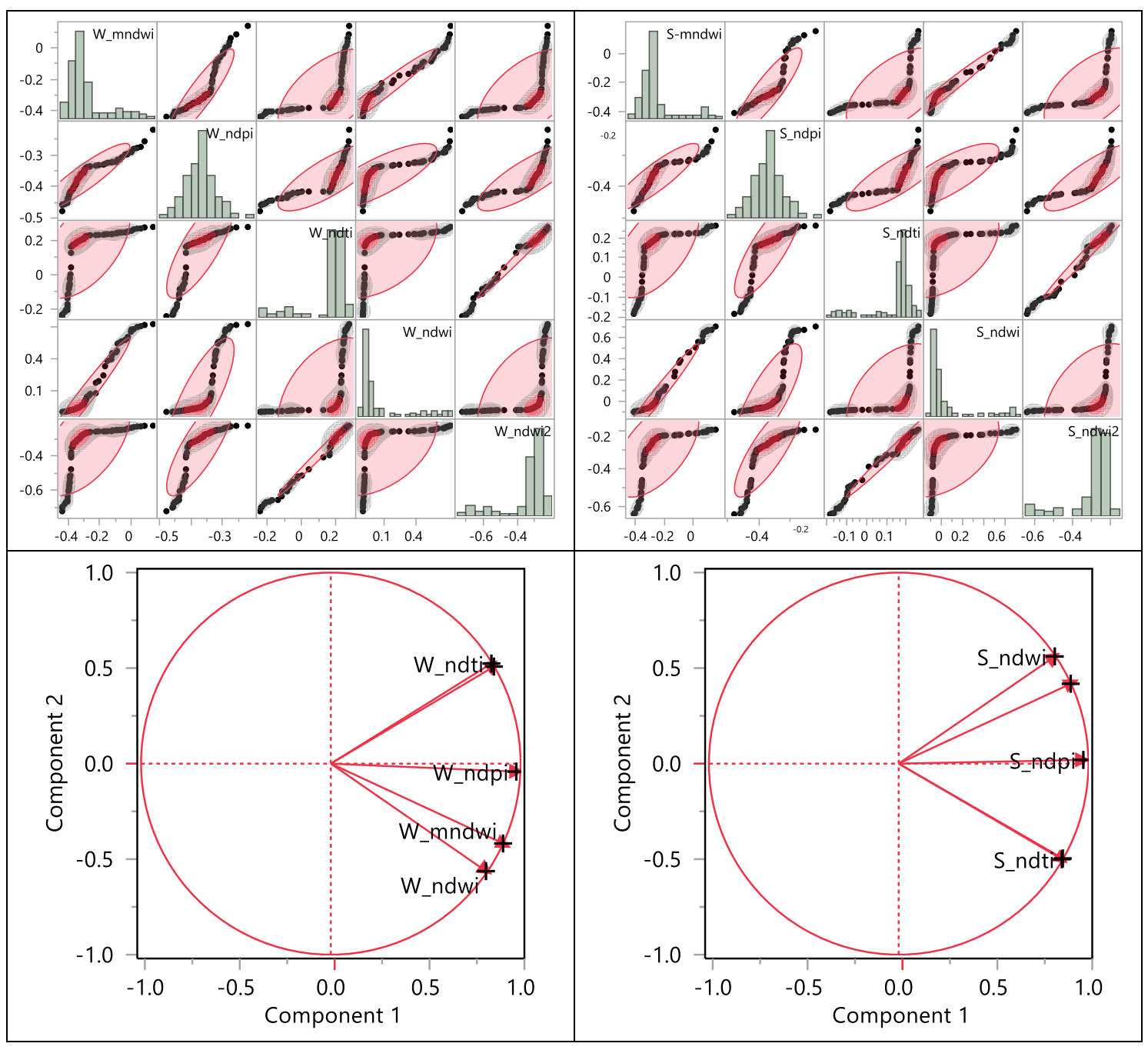

Figure 6. Principal Component Analysis and its correlation matrix of the different water radiometric indices

Table 2. Descriptive statistical analysis and covariant matrix

\begin{tabular}{|c|c|c|c|c|c|c|c|c|c|c|c|c|c|c|}
\hline & \multicolumn{2}{|c|}{ W_mndwi } & \multicolumn{2}{|c|}{\begin{tabular}{l|l|}
$\mathbf{i}$ & W_ndpi
\end{tabular}} & W_ndti & \multirow{2}{*}{\begin{tabular}{|c|c|c|} 
W_ndwi \\
0.9766
\end{tabular}} & W_ndwi2 & \multicolumn{2}{|r|}{ S-mndwi } & \multicolumn{2}{|c|}{ S_ndpi } & S_ndti & S_ndwi & \multirow{2}{*}{\begin{tabular}{|c|c|c|} 
S_ndwi2 \\
0.5787
\end{tabular}} \\
\hline W_mndwi & \multirow{2}{*}{\multicolumn{2}{|c|}{$\frac{1.0000}{0.9025}$}} & \multicolumn{2}{|c|}{0.9025} & 0.5499 & & 0.5677 & S-mndwi & 1.0000 & \multicolumn{2}{|c|}{0.8796} & 0.5742 & 0.9832 & \\
\hline W_ndpi & & & \multicolumn{2}{|c|}{1.0000} & \begin{tabular}{|l|}
0.7874 \\
\end{tabular} & 0.7985 & 0.8125 & S_ndpi & 0.8796 & \multicolumn{2}{|c|}{1.0000} & 0.8085 & \begin{tabular}{|l|}
0.7919 \\
\end{tabular} & 0.8214 \\
\hline W_ndti & \multicolumn{2}{|c|}{0.5499} & 0.7 & 874 & \begin{tabular}{|l|}
1.0000 \\
\end{tabular} & 0.4 & & S_ndti & \begin{tabular}{|l|}
0.5742 \\
\end{tabular} & \multicolumn{2}{|c|}{0.8085} & & & \\
\hline W_ndwi & \multicolumn{2}{|c|}{0.9766} & \multicolumn{2}{|c|}{0.7985} & 0.4068 & 00 & 0. & S_ndwi & 0.9832 & \multicolumn{2}{|c|}{0.7919} & 0.4338 & 1. & 870 \\
\hline W_ndwi2 & \multicolumn{2}{|c|}{0.5677} & \multicolumn{2}{|c|}{0.8125} & \begin{tabular}{|l|}
0.9943 \\
\end{tabular} & 0.4208 & 1.0000 & S_ndwi2 & 0.5787 & \multicolumn{2}{|c|}{0.8214} & 0.9917 & 0.4370 & 1.0000 \\
\hline \multicolumn{8}{|c|}{\begin{tabular}{l|l|l|l|l|l|l}
\multicolumn{1}{|c|}{ Column } & N & DF & Mean & Std dev & Sum & Minimum Maximum
\end{tabular}} & \multicolumn{7}{|c|}{\begin{tabular}{l|l|l|l|l|l|l} 
Column & N & DF & Mean & Std dev & Sum & Minimum|Maximum \\
\end{tabular}} \\
\hline W_mndwi & 150 & 149 & -0.293 & \begin{tabular}{|l|l|}
0.116 \\
\end{tabular} & \begin{tabular}{l|l|}
6 & -44.003 \\
\end{tabular} & -0.437 & & $\begin{array}{l}\text { S-mndwi } 1 \\
\end{array}$ & \begin{tabular}{|l|l|l}
150 & 149 & -1 \\
\end{tabular} & -0.256 & 0.120 & \begin{tabular}{l|l|}
0 & -38.480 \\
\end{tabular} & -0.410 & 0.152 \\
\hline $\begin{array}{l}\text { W_ndpi } \\
\end{array}$ & \begin{tabular}{|l|}
150 \\
\end{tabular} & 149 & -0.370 & \begin{tabular}{|l|}
0.043 \\
\end{tabular} & \begin{tabular}{|l|l|}
3 & -55.538 \\
\end{tabular} & -0.478 & -0.219 & \begin{tabular}{l|l} 
S_ndpi & 1
\end{tabular} & \begin{tabular}{|l|l|l|}
150 & 149 & -1 \\
\end{tabular} & -0.370 & 0.043 & \begin{tabular}{|l|l|}
3 & -55.538 \\
\end{tabular} & -0.478 & -0.219 \\
\hline W_ndti & 150 & \begin{tabular}{l|l}
149 & ( \\
\end{tabular} & 0.157 & 0.121 & $\begin{array}{ll}123.610 \\
\end{array}$ & -0.243 & & S_ndti & \begin{tabular}{|l|l|l|}
150 & 149 & 0 \\
\end{tabular} & 0.148 & 0.102 & 222.2081 & -0.182 & 0.260 \\
\hline W_ndwi & 150 & \begin{tabular}{l|l}
149 & ( \\
\end{tabular} & 0.041 & 0.228 & \begin{tabular}{l|l|}
8 & 6.1484 \\
\end{tabular} & -0.104 & 0.73 & S_ndwi & \begin{tabular}{|l|l|l|}
150 & 149 & 0 \\
\end{tabular} & 0.034 & 0.208 & \begin{tabular}{|l|l|} 
& 5.1805 \\
\end{tabular} & -0.106 & 0.708 \\
\hline W_ndwi2 & 150 & \begin{tabular}{l|l}
149 & - \\
\end{tabular} & -0.337 & 0.120 & \begin{tabular}{l|l|}
0 & -50.56 \\
\end{tabular} & -0.722 & -0.224 & \begin{tabular}{l|l} 
S_ndwi2 & 1 \\
\end{tabular} & \begin{tabular}{|l|l|l|}
150 & 149 & -1 \\
\end{tabular} & -0.296 & 0.103 & \begin{tabular}{|l|l|}
3 & -44.436 \\
\end{tabular} & -0.640 & -0.193 \\
\hline
\end{tabular}


Moreover, higher soil water content was related to the improper and intense irrigation systems which are based on the lack of an operative water resource management plan in the designated study area (Koshal, 2012).

The selection of the profound satellite bands adequate for accurate water radiometric mapping is not systematically comprehensive (Lei et al., 2014; Zhang et al., 2013). Spatial inconsistency and land cover dissimilarities are the main controlling factors of the band sensor selection (Allbed and Kumar, 2013; Zhang et al., 2015). Consequently, the utilized water radiometric indices may have different results in specific areas using different band ratios others than the use of Sentinel-2 as a source of remote sensing data (Drusch et al., 2012; Zhu et al., 2015).

\section{Conclusions}

The groundwater resources in the Wadi As-Sirhan are the only water source for the agricultural practices that take place. Therefore, to sustain such agricultural activities in the designated study area an adequate technique of monitoring soil water content is crucial. Remote Sensing data acquired by Sentinel-2 proved to be statistically sufficient to estimate soil water content in two different climatic conditions. The implemented water radiometric indices in the current study can be primarily divided into two groups, climatic condition non-sensitive/ sensitive group. The non-sensitive group contains only the Normalized Difference Pond Index, while the sensitive group contains the rest of the water radiometric indices. Within the second group, there are indices which are less accurate in summer rather than in winter. Modified Normalized Difference Water Index and Normalized Difference Water Index-2 best-fitted winter soil water content estimations. Meanwhile, Normalized Difference Water Index and Normalized Difference Turbidity Index less-fitted winter estimations. However, the Normalized Difference Turbidity Index was statistically proved to be the most defined water radiometric index to estimate soil water content. The current irrigational schemes in Wadi As-Sirhan are not taking into consideration the temporal changes in the climatic conditions, where both summer and winter irrigational schemes are almost the same. Thus, the existing agricultural strategy in Wadi As-Sirhan needs to be revised precisely by the decision makers. Moreover, coherent groundwater resources consumption and soil water content monitoring need to be exercised.

Acknowledgements. This work was supported by the Deanship of Scientific Research (DSR) at King Abdulaziz University, Jeddah, under grant No. (G-192-155-38). The authors, therefore, gratefully acknowledge the DSR technical and financial support.

\section{REFERENCES}

[1] Al-Rashed, M. F., Sherif, M. M. (2000): Water resources in the GCC countries: an overview. - Water Resources Management 14: 59-75.

[2] Allbed, A., Kumar, L. (2013): Soil salinity mapping and monitoring in arid and semi-arid regions using remote sensing technology: a review. - Advances in Remote Sensing 2: 373.

[3] Bahrawi, J. A., Elhag, M. (2016): Simulation of sea level rise and its impacts on the western coastal Area of Saudi Arabia. - Indian Journal of Geo-Marine Sciences 45: 5461 . 
[4] Bahrawi, J. A., Elhag, M., Aldhebiani, A. Y., Galal, H. K., Hegazy, A. K., Alghailani, E. (2016): Soil erosion estimation using remote sensing techniques in Wadi Yalamlam Basin, Saudi Arabia. - Advances in Materials Science and Engineering. http://dx.doi.org/10.1155/2016/9585962.

[5] Beisl, U, Telaar, J., Schönermark, M. V. (2008): Atmospheric correction, reflectance calibration and BRDF correction for ADS40 image data. - International Archives of the Photogrammetry, Remote Sensing and Spatial Information Sciences 37: 7-12.

[6] Chauhan, N. S. (2003): Spaceborne soil moisture estimation at high resolution: a microwave-optical/IR synergistic approach. - International Journal of Remote Sensing 24: 4599-622.

[7] Chavez, P. S. (1996): Image-based atmospheric corrections-revisited and improved. Photogrammetric Engineering and Remote Sensing 62: 1025-35.

[8] Chen, Z. (2006): Effects of fire on major forest ecosystem processes: an overview. - Ying Yong Sheng Tai Xue Bao 17: 1726-32.

[9] Congalton, R. G., Oderwald, R. G., Mead, R. A. (1983): Assessing Landsat classification accuracy using discrete multivariate analysis statistical techniques. - Photogrammetric Engineering and Remote Sensing 49: 1671-78.

[10] Crippen, R. E. (1990): Calculating the vegetation index faster. - Remote Sensing of Environment 34: 71-73.

[11] Dambach, P., Machault, V., Lacaux, J.-P., Vignolles, C., Sié, A., Sauerborn, R. (2012): Utilization of combined remote sensing techniques to detect environmental variables influencing malaria vector densities in rural West Africa. - International Journal of Health Geographics 11: 8.

[12] Dasgupta, S. (2007): Remote sensing techniques for vegetation moisture and fire risk estimation. - Ph.D. Dissertation, George Mason University, Virginia, USA.

[13] Daughtry, C. S. T., Hunt, E. R., Doraiswamy, P. C., McMurtrey, J. E. (2005): Remote sensing the spatial distribution of crop residues. - Agronomy Journal 97: 864-71.

[14] Dehni, A., Lounis, M. (2012): Remote sensing techniques for salt affected soil mapping: application to the Oran region of Algeria. - Procedia Engineering 33: 188-98.

[15] Drusch, M., Del Bello, U., Carlier, S., Colin, O., Fernandez, V., Gascon, F., Hoersch, B., Isola, C., Laberinti, P., Martimort, P. (2012): Sentinel-2: ESAs optical high-resolution mission for GMES operational services. - Remote Sensing of Environment 120: 25-36.

[16] Du, Z., Li, W., Zhou, D., Tian, L., Ling, F., Wang, H., Gui, Y., Sun, B. (2014): Analysis of Landsat-8 OLI imagery for land surface water mapping. - Remote Sensing Letters 5: 672-81.

[17] Elhag, M. (2016): Evaluation of different soil salinity mapping using remote sensing techniques in arid ecosystems, Saudi Arabia. - Journal of Sensors. http://dx.doi.org/10.1155/2016/7596175.

[18] Elhag, M., Bahrawi, J. A. (2014a): Conservational use of remote sensing techniques for a novel rainwater harvesting in arid environment. - Environmental Earth Sciences 72: 4995-5005.

[19] Elhag, M., Bahrawi, J. A. (2014b): Potential rainwater harvesting improvement using advanced remote sensing applications. - Scientific World Journal. http://dx.doi.org/10.1155/2014/806959.

[20] Elhag, M., Bahrawi, J. A. (2017a): Realization of daily evapotranspiration in arid ecosystems based on remote sensing techniques. - Geoscientific Instrumentation, Methods and Data Systems 6: 141.

[21] Elhag, M., Bahrawi, J. A. (2017b): Soil salinity mapping and hydrological drought indices assessment in arid environments based on remote sensing techniques. Geoscientific Instrumentation, Methods and Data Systems 6: 149.

[22] Engman, E. T. (1991): Applications of microwave remote sensing of soil moisture for water resources and agriculture. - Remote Sensing of Environment 35: 213-26. 
[23] FAO (1998): Guidelines for Computing Crop Water Requirements. - FAO Irrigation and Drainage Paper 56. FAO, Rome.

[24] Ganaie, H. A., Hashaia, H., Kalota, D. (2013): Delineation of flood prone area using Normalized Difference Water Index (NDWI) and transect method: A case study of Kashmir Valley. - International Journal of Remote Sensing Applications 3: 53-58.

[25] Gao, B.-C. (1996): NDWI-A normalized difference water index for remote sensing of vegetation liquid water from space. - Remote Sensing of Environment 58: 257-66.

[26] Gautam, V .K., Gaurav, P. K., Murugan, P., Annadurai, M. (2015): Assessment of surface water dynamics in Bangalore using WRI, NDWI, MNDWI, supervised classification and KT transformation. - Aquatic Procedia 4: 739-46.

[27] Gidey, E., Dikinya, O., Sebego, R., Segosebe, E., Zenebe, A. (2018): Modeling the spatio-temporal meteorological drought characteristics using the standardized precipitation index (SPI) in Raya and its environs, Northern Ethiopia. - Earth Systems and Environment. DOI: 10.1007/s41748-018-0057-7.

[28] Gu, Y., Brown, J. F., Verdin, J. P. Wardlow, B. (2007): A five-year analysis of MODIS NDVI and NDWI for grassland drought assessment over the central Great Plains of the United States. - $\quad$ Geophysical Research Letters 34. https://doi.org/10.1029/2006GL029127.

[29] Hawkins, R. H., Pole, R. A. (1989): Standardization of peak-volume transformations. JAWRA Journal of the American Water Resources Association 25: 377-80.

[30] Hoetzl, H. (1995): Groundwater recharge in an arid karst area (Saudi Arabia). - IAHS Publications-Series of Proceedings and Reports-Intern Assoc Hydrological Sciences 232: 195-210.

[31] Ji, L., Zhang, L., Wylie, B. (2009): Analysis of dynamic thresholds for the normalized difference water index. - Photogrammetric Engineering \& Remote Sensing 75: 1307-17.

[32] Klute, A. (1986): Methods of Soil Analysis, Part 1. Physical and Mineralogical Properties. - American Society of Agronomy, Madison, WI.

[33] Koshal, A. K. (2012): Spectral characteristics of soil salinity areas in parts of South-West Punjab through remote sensing and GIS. - International Journal of Remote Sensing and GIS 1: 84-89.

[34] Lacaux, J. P., Tourre, Y. M., Vignolles, C., Ndione, J. A., Lafaye, M. (2007): Classification of ponds from high-spatial resolution remote sensing: Application to Rift Valley Fever epidemics in Senegal. - Remote Sensing of Environment 106: 66-74.

[35] Lei, L., Tiyip, T., Jiang, H.-N., Kelimu, A. (2014): Study on the soil salinization monitoring based on measured hyperspectral and HSI data. - Spectroscopy and Spectral Analysis 34: 1948-53.

[36] Li, W., Du, Z., Ling, F., Zhou, D., Wang, H., Gui, Y., Sun, B., Zhang, X. (2013): A comparison of land surface water mapping using the normalized difference water index from TM, ETM+ and ALI. - Remote Sensing 5: 5530-49.

[37] Lillesand, T., Kiefer, R. W., Chipman, J. (2014): Remote sensing and image interpretation. - John Wiley \& Sons, Hoboken.

[38] Mathieu, R., Pouget, M., Cervelle, B., Escadafal, R. (1998): Relationships between satellite-based radiometric indices simulated using laboratory reflectance data and typic soil color of an arid environment. - Remote Sensing of Environment 66: 17-28.

[39] McFeeters, S. K. (1996): The use of the Normalized Difference Water Index (NDWI) in the delineation of open water features. - International Journal of Remote Sensing 17: 1425-32.

[40] Moghadas, D., Jadoon, K. Z., Vanderborght, J., Lambot, S., Vereecken, H. (2013): Effects of near surface soil moisture profiles during evaporation on far-field groundpenetrating radar data: A numerical study. - Vadose Zone Journal 12. DOI: 10.2136/vzj2012.0138.

[41] Monahan, A. H. (2000): Nonlinear principal component analysis by neural networks: theory and application to the Lorenz system. - Journal of Climate 13: 821-35. 
[42] Muñoz-Carpena, R., Li, Y. C., Klassen, W., Dukes, M. D. (2005): Field comparison of tensiometer and granular matrix sensor automatic drip irrigation on tomato. HortTechnology 15: 584-90.

[43] Muñoz-Carpena, R., Regalado, C. M., Álvarez-Benedi, J., Bartoli, F. (2002): Field evaluation of the new Philip-Dunne permeameter for measuring saturated hydraulic conductivity. - Soil Science 167: 9-24.

[44] Mustafa, A., Rahman, G. (2018): Assessing the spatio-temporal variability of meteorological drought in Jordan. - Earth Systems and Environment. DOI: 10.1007/s41748-018-0071-9.

[45] Myneni, R. B, Hall, F. G., Sellers, P. J., Marshak, A. L. (1995): The interpretation of spectral vegetation indexes. - IEEE transactions on Geoscience and Remote Sensing 33: 481-86.

[46] Ochsner, T. E, Cosh, M. H., Cuenca, R. H., Dorigo, W. A., Draper, C. S., Hagimoto, Y., Kerr, Y. H., Njoku, E. G., Small, E. E., Zreda, M. (2013): State of the art in large-scale soil moisture monitoring. - Soil Science Society of America Journal 77: 1888-919.

[47] Palecki, M. A., Bell, J. E. (2013): US Climate Reference Network soil moisture observations with triple redundancy: Measurement variability. - Vadose Zone Journal 12. https://doi.org/10.2136/vzj2012.0158.

[48] Psilovikos, A., Elhag, M. (2013): Forecasting of remotely sensed daily evapotranspiration data over Nile Delta region, Egypt. - Water Resources Management 27: 4115-30.

[49] Sánchez-Ruiz, S., Piles, M., Sánchez, N., Martínez-Fernández, J., Vall-llossera, M., Camps, A. (2014): Combining SMOS with visible and near/shortwave/thermal infrared satellite data for high resolution soil moisture estimates. - Journal of Hydrology 516: 273-83.

[50] Şen, Z., Al-Harithy, S., As-Sefry, S., Almazroui, M. (2017): Aridity and risk calculations in saudi arabian wadis: Wadi Fatimah case. - Earth Systems and Environment 1: 26.

[51] Serbin, G., Hunt, E. R., Daughtry, C. S. T., McCarty, G. W., Doraiswamy, P. C. (2009): An improved ASTER index for remote sensing of crop residue. - Remote Sensing 1: 97191.

[52] Singh, K. V., Setia, R. Sahoo, S., Prasad, A., Pateriya, B. (2015): Evaluation of NDWI and MNDWI for assessment of waterlogging by integrating digital elevation model and groundwater level. - Geocarto International 30: 650-61.

[53] Soti, V., Tran, A., Bailly, J.-S., Puech, C., Seen, D. L., Bégué, A. (2009): Assessing optical earth observation systems for mapping and monitoring temporary ponds in arid areas. - International Journal of Applied Earth Observation and Geoinformation 11: 34451.

[54] Su, Z., Troch, P. A., Troch, F. P. De, Nochtergale, L., Cosyn, B. (1995): Preliminary results of soil moisture retrieval from ESAR (EMAC 94) and ERS-1/SAR. Part II: Soil moisture retrieval. - In: Proceedings of the Second Workshop on Hydrological and Microwave Scattering Modelling for Spatial and Temporal Soil Moisture Mapping from ERS-1 and JERS-1.

[55] Thompson, D. R, Natraj, V., Green, R. O., Helmlinger, M. C., Gao, B.-C. Eastwood, M. L. (2018): Optimal estimation for imaging spectrometer atmospheric correction. Remote Sensing of Environment 216: 355-73.

[56] Walker, J. P. (1999): Estimating soil moisture profile dynamics from near-surface soil moisture measurements and standard meteorological data. - University of Newcastle, New South Wales, Australia.

[57] Wang, Y., Huang, F., Wei, Y. (2013): Water body extraction from LANDSAT ETM+ image using MNDWI and KT transformation. - In: Geoinformatics (GEOINFORMATICS), 2013 21st International Conference, 1-5. IEEE.

[58] Watson, D. M., Doerr, V. A. J., Banks, S. C., Driscoll, D. A., van der Ree, R., Doerr, E. D., Sunnucks, P. (2017): Monitoring ecological consequences of efforts to restore landscape-scale connectivity. - Biological Conservation 206: 201-09. 


$$
-303-
$$

[59] Wood, E. F., Lettenmaier, D. P., Zartarian, V. G. (1992): A land-surface hydrology parameterization with subgrid variability for general circulation models. - Journal of Geophysical Research: Atmospheres 97: 2717-28.

[60] Xu, H. (2006): Modification of normalised difference water index (NDWI) to enhance open water features in remotely sensed imagery. - International Journal of Remote Sensing 27: 3025-33.

[61] Zhang, C. W., Tang, J. K., Yu, X. J., Wang, C. L., Mi, S. J. (2013): Quantitative retrieval of soil salt content based on remote sensing in the Yellow River delta. - Journal of Graduate University of Chinese Academy of Sciences 30: 220-27.

[62] Zhang, H.-W., Chen, H.-L. (2016): The application of modified normalized difference water index by leaf area index in the retrieval of regional drought monitoring. - DEStech Transactions on Engineering and Technology Research. DOI: 10.5194/isprsarchives-XL7-W3-141-2015.

[63] Zhang, T., Zhao, G., Chang, C., Wang, Z., Li, P., An, D., Jia, J. (2015): Information extraction method of soil salinity in typical areas of the yellow river delta based on landsat imagery. - Agricultural Sciences 6: 71.

[64] Zhu, Y., Ren, L., Lu, H. Skaggs, T. H. (2008): Determination of root-zone water storage in a desert woodland using a two-layer moisture balance model. - IAHS Publication 322: 246.

[65] Zhu, Z., Wang, S., Woodcock, C. E. (2015): Improvement and expansion of the Fmask algorithm: cloud, cloud shadow, and snow detection for Landsats 4-7, 8, and Sentinel 2 images. - Remote Sensing of Environment 159: 269-77. 